\title{
CAUDAL DUPLICATION SYNDROME
}

\author{
Atul Kumar Taneja', Geazi Zaffani², Augusto Celso Scarparo Amato-Filho, \\ Luciano de Souza Queiroz ${ }^{4}$, Verônica de Araújo Zanardi ${ }^{5}$, José Ribeiro de Menezes-Netto ${ }^{6}$
}

We report a rare case of caudal duplication syndrome, a disorder associating partial or complete duplication of the spine/spinal cord and of other caudal structures, specially gastrointestinal and urogenital tracts, and variable degrees of neurological dysfunction.

\section{CASE}

A female infant, born by cesarean delivery (dilation dystocia), was referred to our service at age of 24 hours with a history of "imperforate anus". Physical examination revealed duplicity of the vulvar introit (urine output by the right orifice and feces by the left). She was submitted to the following imaging exams: (1) echodopplercardiogram - interatrial and interventricular communications; (2) ultrasonography - pelvic left kidney; (3) barium ene- ma - one of the perineal orifices had a communication with the rectum; the other communicated with the vaginal dome and the bladder (urogenital sinus); (4) voiding cystourethrogram (VCU) - two urethral orifices communicating with the bladder, bladder diverticulum on the right side and vesico-ureteral reflux (grade II) on the left side.

Investigation of the spine was done with conventional radiographs (XR), computed tomography (CT) and magnetic resonance imaging (MRI), which disclosed complex malformations of the thoracic and lumbosacral spine, with " $\mathrm{S}$ " shaped dextroscoliolis. Aortic duplication was also noted (Fig 1). The vertebral bodies of T1, T2, T4 and T10 were widened and split by an anterior median incisure. A T7 hemivertebra was also present. From T11 level there was complete duplication of the vertebral bodies extending
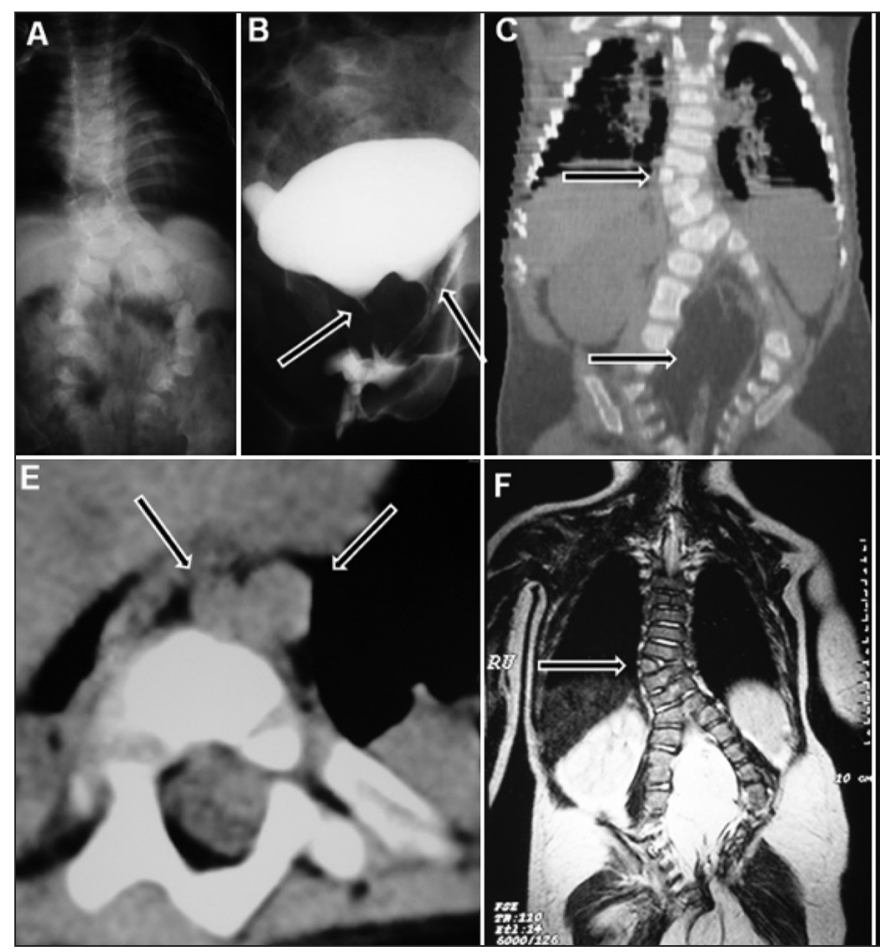
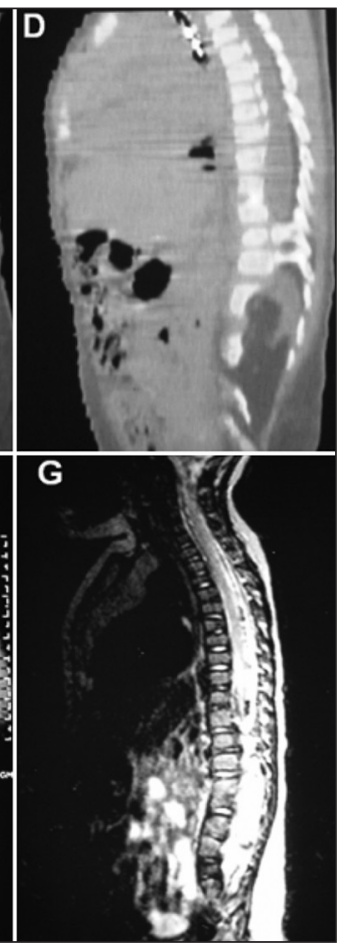

Fig 1. [A] Radiograph of the spine shows complex malformation with complete duplication of the lowerthoracic and lumbar vertebral bodies, and sacrococcigeal agenesis. [B] voiding cystourethrogram - two urethral orifices communicating with the bladder (arrows) and bladder diverticulum on the right side. The coronal CT and MR T2-weighted images [C, F] demonstrate the hemivertebra (upper arrow) and partially or completely duplicated vertebral bodies. The lipoma (lower arrow) inside the spinal canal is also evident on the sagital images. $[D, G]$ In the sagittal plane, agenesis of sacrococcigeal vertebrae is also apparent. [E] (axial CT) shows aortic duplication (arrows).

\section{SÍNDROME DA DUPLICAÇÃO CAUDAL}

Clinics Hospital (HC), Faculty of Medical Sciences (FCM), State University of Campinas (UNICAMP), Campinas, São Paulo, Brazil (FCM/UNICAMP): 'Resident, Department of Radiology; ${ }^{2}$ Former Resident, Department of Radiology; ${ }^{3}$ Assistant Radiologist, Department of Radiology; ${ }^{4}$ Professor, Department of Pathology; ${ }^{5}$ Professor, Department of Radiology; ${ }^{6} \mathrm{MRI}$ Division Chief, Department of Radiology.

Received 7 February 2009, received in final form 25 May 2009. Accepted 11 June 2009.

Dr. Atul Kumar Taneja - Rua Oscar Freire 2040 / 164 - 05409-011 São Paulo SP - Brasil. E-mail: atultaneja@gmail.com 

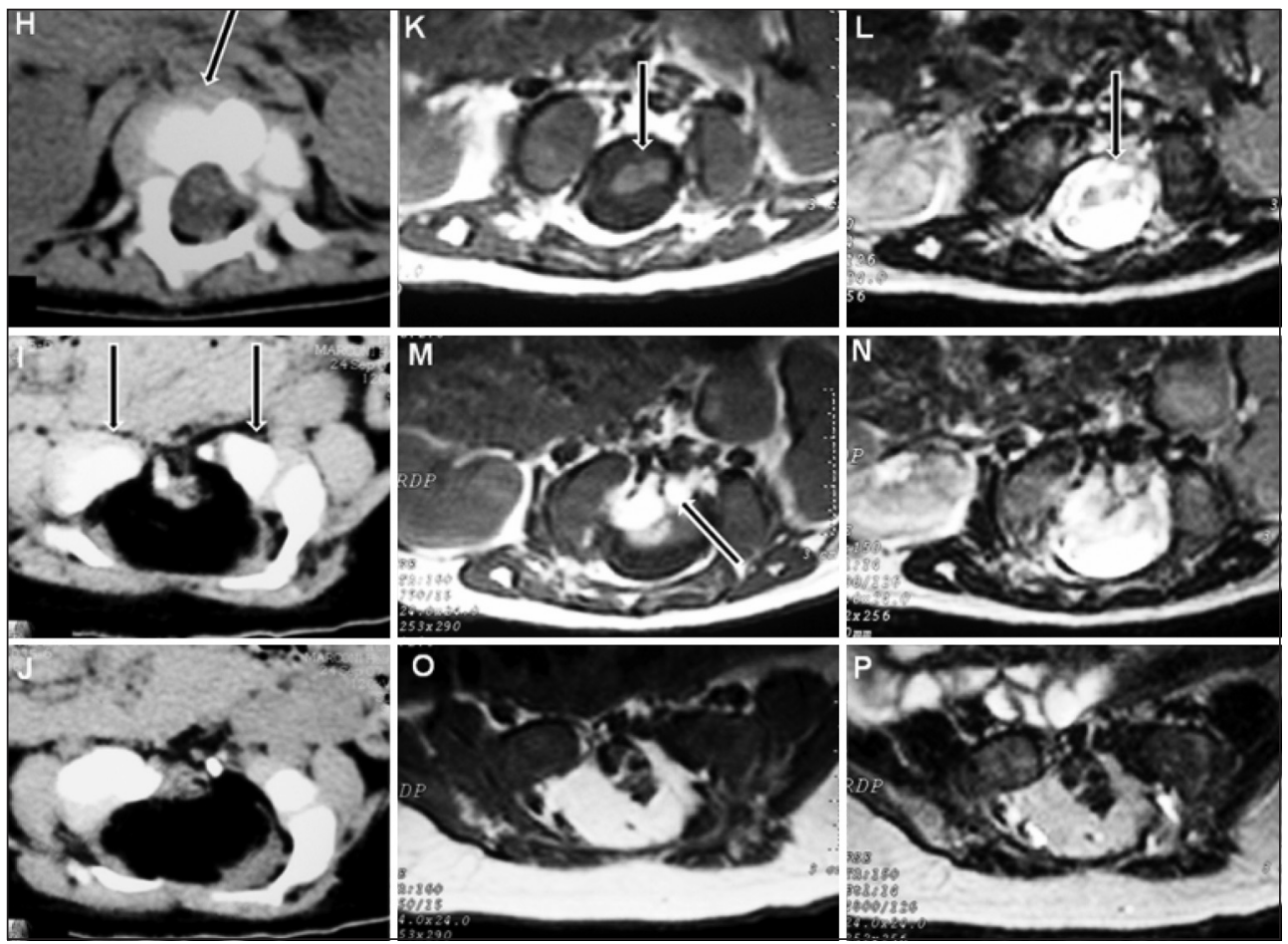

Fig 2. Axial CT images: partial split [H - arrow] and complete duplication of the vertebral bodies [I, J - arrows], deformity of the laminae, and lipoma within the enlarged spinal canal. Axial MR T1 and T2-weighted images: duplication of the spinal cord [K, L-arrows] and lipoma [O, P]. A septum interposes between the dural sacs (Pang type I duplication) [M, N-arrow].

down to the S2 level. The remaining sacral and coccigeal vertebrae were absent. Duplicated vertebrae were joined posteriorly by deformed laminae and encompassed an extremely enlarged spinal canal. The spinal cord was duplicated from level T1 downwards. From L1 level, a large lipoma occupied the spinal canal and communicated with the subcutaneous tissues inferiorly (Fig 2).

\section{DISCUSSION}

Spinal and spinal cord duplicity (diastematomyelia) malformations span a wide spectrum of anomalies, ranging from a simple fibrous band splitting the cord into halves to complete duplication of the spine and spinal cord. The more serious forms are rare and only a limited number of cases are on record'. They are usually associated with other systemic malformations, including duplication of vascular structures, of the distal gastrointestinal and urogenital tracts (as in the present case), and possibly limb malformations. The term caudal duplication syndrome has been applied to those instances.

The embryologic origin of the caudal duplication is not known. Some authors propose that it may result from incomplete division of monozygotic twins. Pang et al. ${ }^{2}$ advanced a unified theory for the spinal cord duplication disorders, suggesting that all result from abnormal adher- ence between ectoderm and endoderm ${ }^{2}$. In the view of Dominguez et al. these anomalies originate from damage to the mass formed by caudal cells and posterior gut at approximately 25 days of pregnancy?.

Pang et al. classified spinal cord duplication anomalies into types I and II. The first is characterized by two hemicords, each contained within its own dural sac, and separated by an osteocartillaginous septum. Type II is defined by two hemicords in the same dural sac, separated by a fibrous septum ${ }^{2,3}$. The case we report may be classified as type I.

Most cases present with severe neurological impairment, although a few patients with mild or absent neurological dysfunction are on record $d^{4,5}$.

\section{REFERENCES}

1. Dominguez R, Rott J, Castillo M, Pittaluga RR, Corriere JN Jr. Caudal duplication syndrome. Am J Dis Child 1993;147:1048-1052.

2. Pang D, Dias MS, Ahab-Barmada M. Split cord malformation: Part I. A unified theory of embryogenesis for double spinal cord malformations. Neurosurgery 1992;31:451-480.

3. Pang D, Dias MS, Ahab-Barmada M. Split cord malformation. Part II: Clinical syndrome. Neurosurgery 1992;31:481-500.

4. Incesu L, Karaismailoglu TN, Selcuk MB. Neurologically normal complete asymmetric lumbar spine duplication. AJNR Am J Neuroradiol 2004;25:895-896.

5. Ahmed S, Xenos C, Hockley AD. Thoraco-lumbar duplication of the spine: case report and embryology review. Childs Nerv Syst 2000;16: 603-606. 